\title{
Using gene carrier probability to select high risk families for identifying germline mutations in breast cancer susceptibility genes
}

Jenny Chang-Claude, Juan Dong, Silke Schmidt, Maryam Shayeghi, Dymitr Komitowski, Heiko Becher, Michael R Stratton, Brigitte Royer-Pokora

\begin{abstract}
Germline mutations in highly penetrant autosomal dominant genes explain about $5 \%$ of all breast cancer, and heritable mutations in the BRCA1 breast and ovarian cancer susceptibility gene account for 2-3\% of breast cancer in the general population. Nevertheless, the presence of such mutations is highly predictive of disease development. Since screening for mutations is still technically laborious, we investigated whether the prior probability of being a carrier of a dominant breast cancer susceptibility gene in the youngest affected family member could be used to identify families in which the probability of finding a mutation is sufficiently high. Sixty German families with three or more cases of breast/ovarian cancer with at least two cases diagnosed under the age of 60 were screened for mutations by SSCP/ CSGE and subsequent direct sequencing. Thirteen germline truncating/splicing mutations in BRCA1 were found in 33\% (6/18) of the breast-ovarian cancer families and in $17 \%(7 / 42)$ of breast cancer only families. All the families showing mutations in BRCA1 had carrier probabilities of 0.65 or higher. In families with prior carrier probabilities above 0.6 , the proportion detected was 0.46 in breastovarian cancer families and 0.26 in breast cancer only families. The average age at diagnosis of breast or ovarian cancer in families with BRCA1 mutations was 41.9 years and significantly lower than in families without mutations $(p<0.05)$. Mutation carriers and obligate carriers were also found to have cancers at other sites.
\end{abstract}

The probability of being a susceptibility gene carrier, taking into account the complete pedigree information, allows uniform characterisation of all types of families for identifying those in which mutation analysis for BRCA1/2 is warranted. However, prior probabilities calculated using this method can be reduced when the correlation between genotype and phenotype is imperfect. A larger series of families needs to be investigated in this fashion to provide better estimates of the detection rate for different ranges of carrier probabilities.

$(\Im$ Med Genet 1998;35:116-121)

Keywords: hereditary breast cancer; pedigree; cancer risks
For breast cancer, a positive family history among first degree relatives is reported by $10-12 \%$ of patients and is one of the most important risk factors. Segregation analysis indicates that the familial clustering in some families is accounted for by highly penetrant autosomal dominant genes which explain about $5 \%$ of all breast cancer cases in the general population. ${ }^{1}$ Genetic linkage studies have identified two such rare dominant genes, BRCA1 on chromosome 17q and BRCA2 on chromosome 13q. The first gene predisposing to breast and ovarian cancer, BRCA1, was isolated in 1994 and BRCA2, the second susceptibility gene, was cloned in $1995 .^{2-4}$ The BRCA1 gene is estimated to cause about $2-3 \%$ of all cases of breast cancer. ${ }^{5}$ Women with an inherited mutation in either BRCA1 or BRCA2 have an equally high lifetime risk of about $80 \%$ for breast cancer. However, BRCA1 confers a higher risk for ovarian cancer and BRCA2 for male breast cancer. ${ }^{67}$ Based on a pooled analysis of breast cancer families by the international Breast Cancer Linkage Consortium, it was estimated that BRCA1 accounts for about $75 \%$ of families with multiple cases of early onset breast cancer and ovarian cancer or site specific ovarian cancer only, and for about $40 \%$ of families with breast cancer only. $^{8-10}$

The cloning of the two genes has provided the means to identify mutation carriers and more accurately predict risk of breast and ovarian cancer. However, the BRCA1 gene is composed of 24 exons, covering more than $100 \mathrm{~kb}$ of genomic DNA, and the BRCA2 gene is equally large with 27 exons extending over 70 $\mathrm{kb}$ genomic DNA. ${ }^{4}$ More than 150 distinct germline BRCA1 mutations and more than 70 distinct BRCA2 mutations have so far been found and the numbers are expected to increase further. ${ }^{3411 \cdot 13}$ Involvement of alterations in the regulatory regions is suggested by the failure to detect mutations in some high risk families with substantial evidence for linkage. ${ }^{14-17}$ Such regulatory alterations cannot be easily detected at present. Owing to the large size of the genes and the heterogeneous mutational spectrum, screening for mutations in these genes will remain a technically laborious task except in special populations with some recurring founder mutations, such as in Ashkenazi Jews and the Icelandic, Swedish, and Norwegian populations. ${ }^{18-23}$ For BRCA1, some estimates of the prior probabilities for detecting a mutation in certain family types, 
defined by number and age at diagnosis of breast and ovarian cancer, have been reported and have recently been updated ${ }^{24}$ (D Easton, personal communication). These may be used as a guideline to select high risk families for mutation screening. However, the family types considered do not cover all possible familial constellations and also neglect the effect of the number and ages of unaffected family members. Furthermore, for families ascertained according to common criteria which specify only the affected relatives by number and age of diagnosis, the estimated prior probability for the family to be harbouring highly penetrant susceptibility genes can differ appreciably when the complete pedigree information is taken into account, particularly in pedigrees with smaller numbers of affected members.

We have been systematically collecting German pedigrees with a clustering of breast and ovarian cancer since 1992 in order to study the genetic basis of familial breast cancer. In some of these families, the aggregation of disease may be the result of chance or as yet unidenti-

Table 1 Description of families studied and carrier probabilities in descending order by family type

\begin{tabular}{|c|c|c|c|c|c|c|c|c|c|}
\hline \multirow[b]{2}{*}{ Family $\mathrm{No}^{*}$} & \multicolumn{5}{|c|}{ No of affected } & \multicolumn{3}{|c|}{ Mean age at onset $(y)$} & \multirow[b]{2}{*}{$p \ddagger$} \\
\hline & Allt & $<60$ years & $<50$ years & $B R(b i l) t$ & oVt & $B R$ & $O V$ & $B R / O V$ & \\
\hline \multicolumn{10}{|c|}{ Breast-ovarian cancer families } \\
\hline $2 \$$ & 6 & 5 & 4 & $2 \star \star$ & 5 & 39.50 & 49.20 & 47.83 & 0.992 \\
\hline 805 & 8 & 8 & 8 & $7(3)$ & 1 & 38.71 & 44.00 & 39.38 & 0.991 \\
\hline 709 & 8 & 8 & 7 & 6 & 2 & 47.83 & 39.00 & 45.63 & 0.974 \\
\hline 71 & 4 & 4 & 4 & $3^{\star \star}$ & 2 & 35.67 & 40.00 & 37.50 & 0.974 \\
\hline $142 \S$ & 9 & 8 & 8 & $8(4)$ & 1 & 39.13 & 62.00 & 41.67 & 0.974 \\
\hline $799^{\circ}$ & 6 & 6 & 4 & 4 & 2 & 40.00 & 57.50 & 45.83 & 0.972 \\
\hline 51 & 6 & 5 & 4 & $5^{\star \star}$ & 2 & 48.40 & 54.00 & 50.00 & 0.971 \\
\hline 66 & 5 & 5 & 4 & $4(1)$ & 1 & 39.75 & 53.00 & 42.40 & 0.963 \\
\hline 134 & 4 & 3 & 2 & 3 & 1 & 51.33 & 44.00 & 49.50 & 0.922 \\
\hline 610 & 7 & 6 & 5 & $6(1)$ & 1 & 45.83 & 49.00 & 46.29 & 0.921 \\
\hline 192 & 4 & 4 & 1 & 3 & 1 & 47.67 & 54.00 & 49.25 & 0.912 \\
\hline $166 \$$ & 3 & 3 & 2 & $2(2)$ & 1 & 39.50 & 55.00 & 44.67 & 0.892 \\
\hline 131 & 4 & 3 & 3 & 3 & 1 & 52.33 & 50.00 & 51.75 & 0.564 \\
\hline 141 & 6 & 3 & 2 & 5 & 1 & 40.67 & 54.00 & 44.00 & 0.360 \\
\hline 144 & 5 & 3 & 1 & 4 & 1 & 69.50 & 54.00 & 66.40 & 0.315 \\
\hline 100 & 5 & 3 & 3 & 4 & 1 & 54.25 & 49.00 & 53.20 & 0.062 \\
\hline 90 & 4 & 2 & 0 & 2 & 2 & 57.50 & 67.00 & 62.25 & 0.008 \\
\hline \multicolumn{10}{|c|}{ Breast cancer only families } \\
\hline $95 \$$ & 5 & 5 & 5 & $5(2)$ & & 37.20 & & & 0.990 \\
\hline 815 & 3 & 3 & 3 & $3(1)$ & & 33.33 & & & 0.988 \\
\hline 145 & 4 & 4 & 4 & 4 & & 39.25 & & & 0.984 \\
\hline 62 & 5 & 3 & 2 & 5 & & 49.60 & & & 0.980 \\
\hline $60 \sqrt{2}$ & 6 & 6 & 6 & 6 & & 37.67 & & & 0.974 \\
\hline 72 & 4 & 3 & 3 & $4(2)$ & & 41.00 & & & 0.972 \\
\hline 1699 & 5 & 4 & 2 & $5(1)$ & & 49.00 & & & 0.966 \\
\hline 98 & 4 & 3 & 3 & 4 & & 49.25 & & & 0.962 \\
\hline $103 \pi$ & 7 & 7 & 6 & 7 & & 47.86 & & & 0.958 \\
\hline $105 \S$ & 5 & 4 & 4 & $5(2)$ & & 40.60 & & & 0.958 \\
\hline 189 & 6 & 4 & 2 & $6(2)$ & & 50.25 & & & 0.958 \\
\hline 96 & 6 & 5 & 4 & 6 & & 45.80 & & & 0.956 \\
\hline 87 & 4 & 4 & 3 & $4(1)$ & & 45.75 & & & 0.955 \\
\hline 88 & 3 & 3 & 3 & 3 & & 37.67 & & & 0.950 \\
\hline 99ף & 5 & 4 & 2 & $5(1)$ & & 51.60 & & & 0.940 \\
\hline 128 & 5 & 5 & 2 & $5(1)$ & & 49.20 & & & 0.924 \\
\hline 85 & 6 & 4 & 2 & $6(1)$ & & 55.50 & & & 0.919 \\
\hline 194 & 5 & 3 & 3 & $5(1)$ & & 52.60 & & & 0.919 \\
\hline $147 \S$ & 5 & 5 & 5 & $5(1)$ & & 44.20 & & & 0.910 \\
\hline 73 & 3 & 3 & 3 & 3 & & 38.67 & & & 0.883 \\
\hline 64 & 5 & 5 & 5 & $5(1)$ & & 44.00 & & & 0.879 \\
\hline 136 & 5 & 4 & 2 & $5(2)$ & & 55.00 & & & 0.863 \\
\hline 165 & 6 & 4 & 2 & $6(1)$ & & 55.80 & & & 0.837 \\
\hline 132 & 5 & 4 & 3 & $5(1)$ & & 51.20 & & & 0.783 \\
\hline 94 & 3 & 3 & 2 & 3 & & 46.67 & & & 0.712 \\
\hline $149 \S$ & 3 & 2 & 2 & 3 & & 34.00 & & & 0.674 \\
\hline $104 \S$ & 3 & 2 & 2 & $3(1)$ & & 47.67 & & & 0.647 \\
\hline 175 & 3 & 3 & 2 & $3(2)$ & & 46.30 & & & 0.640 \\
\hline 76 & 4 & 2 & 2 & $4(1)$ & & 52.50 & & & 0.565 \\
\hline 101 & 3 & 3 & 2 & 3 & & 45.67 & & & 0.558 \\
\hline 167 & 3 & 2 & 1 & $3(1)$ & & 55.67 & & & 0.481 \\
\hline 130 & 4 & 3 & 3 & $4(3)$ & & 52.50 & & & 0.416 \\
\hline 67 & 4 & 3 & 2 & 4 & & 54.25 & & & 0.392 \\
\hline 108 & 3 & 2 & 1 & 3 & & 56.67 & & & 0.212 \\
\hline 97 & 4 & 3 & 1 & 4 & & 58.75 & & & 0.208 \\
\hline 86 & 3 & 3 & 2 & $3(1)$ & & 48.67 & & & 0.161 \\
\hline 152 & 3 & 3 & 0 & 3 & & 51.67 & & & 0.157 \\
\hline 78 & 3 & 2 & 2 & 3 & & 51.33 & & & 0.151 \\
\hline 102 & 3 & 3 & 2 & $3(1)$ & & 47.00 & & & 0.148 \\
\hline 3 & 5 & 4 & 2 & 5 & & 55.80 & & & 0.119 \\
\hline 93 & 3 & 3 & 2 & 3 & & 50.67 & & & 0.111 \\
\hline 170 & 3 & 3 & 1 & 3 & & 53.00 & & & 0.101 \\
\hline 140 & 7 & 6 & 3 & 7 & & 50.57 & & & 0.096 \\
\hline
\end{tabular}

*Fictitious family numbers have been generated to maintain confidentiality of patients and their families who were provided with their study numbers in order to elicit information from us for genetic counselling. For scientific purposes, the actual family numbers can be made available upon request.

†All, breast or ovarian cancer; BR (bil), breast cancer (bilateral); OV, ovarian cancer.

$\neq p$, breast cancer gene carrier probability for the youngest affected family member.

SFamilies with BRCA1 mutations.

TFamily includes a male breast cancer case.

$\star \star$ Includes a case with breast and ovarian cancer. 
Table 2 Characteristics of German breast and breast/ovarian families with germline BRCA1 mutations

\begin{tabular}{llllll}
$\begin{array}{l}\text { Family } \\
\text { No }\end{array}$ & $\begin{array}{l}\text { BRCA1 } \\
\text { mutationt }\end{array}$ & $\begin{array}{l}\text { Mean age } \\
\text { BR/OV }\end{array}$ & $\begin{array}{l}\text { Ratio } \\
\text { BR:OV }\end{array}$ & Other cancer sites observed & $\begin{array}{l}\text { Carrier } \\
\text { probability }\end{array}$ \\
\hline 2 & FS & 47.83 & $2: 5$ & - & 0.992 \\
80 & NS & 39.38 & $7: 1$ & Prostate 1 & 0.991 \\
95 & SP & 37.20 & $5: 0$ & Uterus 1 & 0.990 \\
81 & FS & 33.33 & $3: 0$ & Gace 1, liver 1 & 0.988 \\
60 & SP & 37.67 & $6: 0$ & Cervix 1, lung 1 & 0.974 \\
142 & FS & 41.67 & $8: 1$ & Genital organs 1, cervix 1, colon 1 & 0.974 \\
79 & FS & 45.83 & $4: 2$ & Uterus 1, colon 1, lymphatic 1, & 0.958 \\
105 & MS & 40.60 & $5: 0$ & 0.921 \\
61 & NS & 46.29 & $6: 1$ & Ute & \\
147 & NS & 44.20 & $5: 0$ & lung 1 & 0.910 \\
166 & FS & 44.67 & $2: 1$ & Stomach 1, colon 1 & 0.891 \\
149 & FS & 34.00 & $3: 0$ & Cervix 1, uterus 1 & 0.674 \\
104 & NS & 47.67 & $3: 0$ & Bladder 1, lung 1, testicle 1 & 0.647 \\
\hline
\end{tabular}

^Family numbers are fictitious (see footnote to table 1). †FS, frameshift; MS, missense; SP, splice; NS, nonsense.

$\ddagger B R$, breast cancer; OV, ovarian cancer

fied breast cancer genes of lower penetrance than BRCA1/2. Since screening for mutations is very cost and time intensive, we investigated whether the prior probability of being a carrier of a dominant breast cancer susceptibility gene in the youngest affected family member could be used to identify families in which the probability of finding a mutation is sufficiently high. Here, we report the results from BRCA1 mutation screening of a defined set of families characterised additionally by the probability of segregating breast and ovarian cancer predisposing genes.

\section{Subjects and methods \\ FAMILIES}

Families containing three or more members in the same lineage affected with breast/ovarian cancer with at least two diagnosed under the age of 60 years were ascertained through gynaecologists or in response to press publicity in Germany. Each pedigree was extended through an index case and available related family members. The investigations were approved by the Ethics Committee of the University of Heidelberg and informed consent was obtained from all study participants. All diagnoses of cancer were researched and verified through pathology reports or death certificates, where possible. Blood samples were obtained from as many living relevant family members as possible and tumour samples embedded in paraffin from all cancer cases were requested when available. A selfadministered questionnaire was used to elicit information on demographic and epidemiological risk factors for breast cancer. A subset of families was previously included in linkage studies; however, most families were too small for reliable linkage analysis. ${ }^{25}$

Table 3 Detection of BRCA1 mutations in families by carrier probability and family type

\begin{tabular}{|c|c|c|c|c|c|c|}
\hline \multirow{2}{*}{$\begin{array}{l}\text { Carrier probability } \\
\text { (range) }\end{array}$} & \multicolumn{3}{|c|}{ No of families } & \multicolumn{3}{|c|}{$\begin{array}{l}\text { No of families with BRCA1 mutations } \\
\text { (proportion) }\end{array}$} \\
\hline & All & Breast & Breast-ovarian & All & Breast & Breast-ovarian \\
\hline $0.9-1.0$ & 31 & 20 & 11 & $10(0.32)$ & $5(0.25)$ & $5(0.45)$ \\
\hline $0.6-0.9$ & 9 & 7 & 2 & $3(0.33)$ & $2(0.29)$ & $1(0.50)$ \\
\hline $0.4-0.6$ & 5 & 4 & 1 & 0 & 0 & 0 \\
\hline $0-0.4$ & 15 & 11 & 4 & 0 & 0 & 0 \\
\hline Total & 60 & 42 & 18 & $13(0.22)$ & $7(0.17)$ & $6(0.33)$ \\
\hline
\end{tabular}

Sixty families were screened for mutations in the BRCA1 gene by single strand conformation polymorphism analysis (SSCP) or conformation sensitive gel electrophoresis (CSGE) of all exons and flanking intron regions using published primers ${ }^{1526}$ followed by direct sequencing, as reported by Dong et al. ${ }^{27}$ Lymphocytic genomic DNA from one or two affected members per family was used as a template in the mutation analysis. Owing to the possible inclusion of sporadic cases, particularly in families without haplotypes of BRCA1 markers, two young affected persons were analysed where possible.

\section{STATISTICAL ANALYSIS}

As a measure of genetic risk that can be derived without genotyping, the probability of being a carrier of a dominant breast cancer gene was calculated for the youngest breast cancer patient in each family under the established genetic model for breast cancer. $F$ denotes a given pedigree including genealogical relationships, ages, and disease phenotypes of all members. With the MLINK component of the linkage analysis package LINKAGE, ${ }^{28}$ we calculated the probability for the youngest affected family member in pedigree $F$ to be carrying a mutant allele (BRCA1 or BRCA 2 or other dominant genes) under the genetic model derived by Claus et $a l^{29}$ and modified by Narod et al. ${ }^{9}$ This probability is given by the ratio of the likelihood of $F$ when the proband has the high risk genotype $g$ over the likelihood of $F$ when the sum over all possible genotypes $h$ is taken, that is,

$$
P(\mathrm{gl} F)=P(F, g) / P(F)=P(F, g) / \sum_{h} P(F, h)(1) .^{30}
$$

Marker data, which are required as input into the LINKAGE program, are set to zero for this application. We assumed the penetrance parameters used by Narod et al for the analysis of Breast Cancer Linkage Consortium data. Under this model, breast cancer susceptibility confers a breast cancer cumulative risk that is $71 \%$ by the age of 70 years and an ovarian cancer cumulative risk that is $42 \%$ by the age of 70 years. To implement this model in LINKAGE, family members were assigned to 21 liability classes defined by (1) affected status, (2) site of cancer (breast or ovarian), and (3) age at cancer diagnosis or at last observation, using the seven age groups <30, 30-39, 40-49, 50-59, $60-69,70-79$, and $\geqslant 80$ years. Unaffected males were assigned to the liability class of females unaffected up to age 29 , approximately equivalent to being of unknown carrier status. Females affected with both breast and ovarian cancer and males affected with breast cancer were assigned to the liability class of females affected in the youngest age group, thus maximising their probability to be gene carriers. The calculated carrier probability is supposed to predict the likelihood of finding either BRCA1 or BRCA2 mutations. Thus, we assumed a combined gene frequency of mutant BRCAx alleles of 0.0033 , as in the CASH model derived by Claus et al. ${ }^{29}$ 




$\begin{array}{ll}\Delta \text { Breast cancer only family } & \Delta \text { Breast cancer family with mutation } \\ \square \text { Breast/ovarian family } & \text { - Breast/ovarian family with mutation }\end{array}$

Figure 1 Scattergram of 13 BRCA1 mutations detected in 60 German breast/ovarian cancer families by carrier probability and mean age at onset of breast or ovarian cancer.

\section{Results}

The 60 families studied included 18 families with breast and ovarian cancer and 42 families with breast cancer only. Male breast cancer was observed in four families. The number of subjects affected with breast/ovarian cancer per family ranged between three and nine with a mean of 4.6 (table 1). We have been able to verify the diagnosis through pathology reports for $59 \%(151 / 255)$ of the breast cancers and $50 \%(13 / 26)$ of the ovarian cancers in the families. The mean age at diagnosis ranged between 33.3 and 69.5 years for breast cancer and between 39.0 and 67.0 years for ovarian cancer. In 38 families (63\%) the mean age at diagnosis of breast cancer or ovarian cancer was under 50 years and in 10 families (17\%) under 40 years of age. Carrier probabilities for the youngest affected family member ranged between 0.008 and 0.992 and were above 0.9 in 31 families (52\%).

Germline chain terminating/splicing mutations in BRCA1 were detected in 13 families $(22 \%)$, including six breast-ovarian cancer families and seven families with female breast cancer only. Eleven of the mutations were unique and included five frameshift deletions, three nonsense mutations, two splice variant mutations, and one missense mutation (table 2 ). The two splice site mutations changed a conserved splice donor site, in one instance, and a conserved splice acceptor site in the other. Thus they are likely to affect the correct splicing of the transcript. The missense mutation is located in the ring finger domain and has been reported in other BRCA1 families. There was no obvious difference in mutation site between those detected in families with and without ovarian cancer. We also found several new polymorphisms and a new unclassified variant in an intron. The polymorphisms were present in both affected and unaffected family members, but the unclassified variant in the intron was only found in a breast cancer patient.
A subset of the families ( 34 out of 60 ) were studied previously for linkage to BRCA1. All three families with clear evidence of linkage to BRCA1 (lod scores above 1.00 at BRCA1) and two of the three families with moderate evidence of linkage (lod scores between 0.7 and 0.8 ) were found to harbour BRCA1 mutations (data not shown). Another three mutations were detected in families with a lod score below 0.3 . However, no mutation was found in one family with a lod score of 0.78 . The remaining five mutations were found in families without previous linkage analysis.

Several cancers other than that of the breast and the ovary were observed among mutation carriers and obligate carriers in these families. Three mutation carriers in families 79,142 , and 149 were affected with squamous cell carcinoma of the cervix at the ages of 31,36 , and 34 years, respectively. Endometrial cancer occurred at the age of 53 in a mutation carrier in family 149 and at the age of 54 in an obligate carrier in family 81 . The male obligate carrier in families 80,61 , and 104 were affected with cancer of the prostate, colon, and bladder, at the age of 80,71 , and 61 years, respectively.

The mutations were found in 10 families showing carrier probabilities above 0.9 and three families with carrier probabilities of 0.65 , 0.68 , and 0.89 . Thus, mutations were detected in $32 \%$ of 31 families with carrier probabilities of above 0.9 and in $33 \%$ of six families with carrier probabilities between 0.6 and 0.9 (table 3 ). This corresponds to mutations in $33 \%$ of the 41 families with carrier probabilities above $0.6,26 \%$ in breast cancer only, and $46 \%$ in breast-ovarian families. In this series of families, the proportion of families with carrier probabilities above 0.6 was slightly higher in breast-ovarian cancer families than in breast cancer only families, being $72 \%(13 / 18)$ and $64 \%$ (27/42), respectively. Overall, BRCA1 mutations were detected in $33 \%$ of the 18 breast-ovarian families and $17 \%$ of the 42 breast cancer only families.

The mean age at diagnosis of breast or ovarian cancer in all the families with BRCA1 mutations was 41.9 years, ranging between 33.3 and 47.8 years. This was significantly lower than the mean of 49.5 years in the other families where no mutations were detected $(p<0.01)$. Given the probability of harbouring a predisposing gene, the mean age at diagnosis appears to further characterise families with mutations in the BRCA1 gene (fig 1).

\section{Discussion}

We investigated whether it is useful to calculate gene carrier probabilities for identifying families in which the probability of finding a mutation is sufficiently high. For the 60 families fulfilling common criteria specifying the number and ages of affected relatives, a total of 13 functionally relevant mutations in BRCA1 were detected by SSCP/CSGE and subsequent DNA sequencing. In all the families harbouring BRCA1 mutations, the probability of being a carrier of a dominant breast cancer gene in the youngest affected family member was 0.65 or higher. In families with carrier probabilities 
above 0.6 , the proportion detected increases to 0.33 overall, 0.46 and 0.26 , respectively, in breast-ovarian cancer and breast cancer only families. If we take into consideration that SSCP/CSGE is reported to have a sensitivity of about $80 \%$, then the number of families with a mutation may actually be higher.

The prior probabilities for BRCA1 from the Breast Cancer Linkage Consortium study were estimated to be 0.33 for families with four or more cases of breast cancer under 60 years only and 0.73 for breast-ovarian families (without male breast cancer) with four or more cases under the age of 60 years (Easton and Ford, in preparation). ${ }^{17}$ Of our 25 families which fall into these categories, BRCA1 mutations were detected in $25 \%(4 / 16)$ of the breast cancer only families and $56 \%(4 / 9)$ of the breastovarian families. Additional prior probabilities for BRCA1 calculated from epidemiological data are 0.30 for families with three cases of breast cancer under 50 years only and 0.17 for two cases of breast cancer under 50 years only (D Easton, personal communication). In our families which fall into these two family types regardless of the total number of affected persons (which is at least three in this study), the proportions with BRCA1 mutations were $14 \%(1 / 7)$ and $16 \%(2 / 12)$, respectively. Even then, of the 60 families studied, we are left with 12 unclassified families, of which one was found to harbour a BRCAl mutation.

When considering only families for which the probability of carrying a breast cancer susceptibility gene in the youngest affected family member is above 0.6 , the proportion of families with detected BRCA1 mutations among breast cancer only families and among families with breast and ovarian cancer are nevertheless both lower than the previously estimated prior probabilities of $30-40 \%$ and $70-80 \%$. Since the published prior probabilities were based predominantly on families with four or more cases selected for early onset breast cancer, these estimates cannot be applied to the majority of families now requesting genetic counselling and gene testing.

The advantage of calculating the probability of being a carrier of a dominant breast cancer susceptibility gene is that it provides a common measure for all pedigrees being counselled. For families in which breast/ovarian cancer cases diagnosed under the age of 60 years have occurred in four or more first degree relatives, the probability of segregating breast cancer predisposing genes will be very high, generally above 0.9 regardless of the size of the complete pedigree. In 17 families with three cases only, we found carrier probabilities that ranged between 0.101 and 0.988 and were above 0.6 in $47 \%$. In another paper we showed that the estimated probability in smaller families with two or three affected members can vary appreciably depending on the number and ages of unaffected family members. ${ }^{31}$ In such moderate risk families, the calculation of the probability of being a carrier of a dominant breast cancer gene may be useful in identifying families in which mutation analysis is warranted.
We recognise, however, several limitations in the interpretation of our results with regard to the applicability of carrier probabilities to identify high risk families and the setting of a threshold for gene testing. The present calculation based on the genetic model used by Narod et $a l^{9}$ assumes age specific penetrances for breast and ovarian cancer with reference to BRCA1. Incorrect specification of penetrances may lead to appreciably different estimates of the carrier probability. ${ }^{32}$ Penetrances for breast cancer appear to be similar for BRCA1 and BRCA2. ${ }^{7}$ It may be justified to assume that penetrances are in the same order of magnitude for other dominant susceptibility genes. The majority of families with a clustering of breast and ovarian cancer are attributed to BRCA1. Further, as yet unidentified dominant breast and ovarian cancer susceptibility genes will probably have negligible effect on the age specific penetrances for ovarian cancer.

Although in the majority of the families the maximal gene carrier probability of all family members is identical to the gene carrier probability for the youngest affected family member (which we have used in this paper), this is not always the case. In another paper (Chang-Claude et al, in preparation), we will report the influence of the two procedures as well as the effect of using different penetrances on the estimates of gene carrier probability.

The carrier probability can be reduced considerably when the correlation between phenotypes and genotypes is imperfect. For the computation, this situation arises not only with incomplete penetrance of the genotype but also when the obligate carrier is affected with cancer at sites other than the expected phenotypes of cancer of the breast or the ovary. In two of our families with a mutation in BRCA1 showing comparatively low carrier probabilities of 0.65 and 0.68 , the obligate carriers were affected with bladder cancer and endometrial cancer, respectively. Increased risks of other cancers in BRCA1 mutation carriers have already been established. ${ }^{33}$ We also observed endometrial cancer, cervical cancer, and colon cancer in mutation carriers and obligate carriers in several families with different mutations. Although not yet formally estimated for BRCA2 mutation carriers, other cancers probably over-represented in BRCA2 mutation carriers include prostate, pancreas, colon, larynx, and ocular melanoma. ${ }^{7212334-36}$ As long as other BRCA1 or BRCA2 associated cancers are not adequately accounted for in the assumed genetic model, the estimated carrier probability will not always be an accurate measure of genetic risk.

It is at present not possible to derive gene specific risks. When the gene frequency and age specific penetrance data for BRCA2, including those for male breast cancer, are available, it will be possible to estimate the probability of carrying a mutation separately for BRCA1 and BRCA2 ${ }^{37}$ At present, families with breast and ovarian cancers would be preferably screened initially for mutations in BRCA1 because of the higher prior probability of BRCA1 being involved. ${ }^{9}$ The presence of male breast cancers 
indicates a greater likelihood of the involvement of BRCA2. We also did not detect any BRCA1 mutations in the families with male breast cancer. The risks for a second primary cancer of the breast and the ovary are known to be high among BRCAl mutation carriers. ${ }^{38}$ Thus bilateral breast cancer may be more frequently associated with BRCA1. Our results suggest that a particularly young average age at diagnosis may characterise families with BRCA1 mutations. Whether the occurrence of bilateral breast cancer and consistent early age at onset preferably indicate the involvement of BRCA1 or BRCA2 will require formal confirmation.

Using the carrier probability as a measure of genetic risk, it remains difficult to determine the threshold at which families should be included in mutation screening for dominant genes. We detected mutations only in families with a carrier probability above 0.6 in the youngest affected person (say, 35 years), which corresponds to a carrier probability of about 0.3 (or above) for an unaffected female first degree relative of the same age. This translates to a phenotypic risk of about 0.3 up to the age of 79 , which corresponds to a relative risk of about 3.0 compared to the general population. At present, we cannot correlate the carrier probabilities with detection of BRCA2. It would be important to screen for BRCA2 mutations in this series of families in order to determine the proportion of the high risk families resulting from BRCA2. The results of the BRCA1 screening suggests that the probability of finding a mutation in families with carrier probabilities of less than $60 \%$ may be very low. Certainly a larger series of families will have to be investigated in this fashion to provide better estimates of the probability of detecting mutations in dominant predisposing genes for the different ranges of carrier probabilities.

We would like to thank all the families for their participation and the clinicians and pathologists for their cooperation in collectin the material. We would also like to thank Evelin Deeg for excellent documentation and data management, and Claudia Steger for expert technical assistance. The support of the Deutsche Krebshilfe ev/Mildred Scheel Foundation is gratefully acknowledged.

1 Eby N, Chang-Claude J, Bishop T. Familial risk and genetic (ancer Causes and Control 1994;5:458-70.

2 Miki Y, Swensen J, Shattuck-Eidens D, et al. A strong candidate for the breast and ovarian cancer susceptibility gene BRCA1. Science 1994;266:66-71.

3 Wooster R, Bignell G, Lancaster J, et al. Identification of the breast cancer susceptibility gene BRCA2. Nature 1995;378: 789-92.

4 Tavtigian SV, Simard J, Rommens J, et al. The complete BRCA2 gene and mutations in chromosome 13q-linked BRCA2 gene and mutations in ch
kindreds. Nat Genet 1996;12:333-7.

5 Ford D, Easton DF, Peto J. Estimates of the gene frequency of BRCAI and its contribution to breast and ovarian cancer incidence. Am $\mathcal{F}$ Hum Genet 1995;57:1457-62.

6 Easton DF, Ford D, Bishop DT. Breast and ovarian cancer incidence in BRCA1-mutation carriers. Breast Cancer Linkage Consortium. Am $\mathcal{F}$ Hum Genet 1995;56:265-71.

7 Stratton MR. Recent advances in understanding of genetic susceptibility to breast cancer. Hum Mol Genet 1996;5: 1515-19.

8 Easton DF, Bishop DT, Ford D, Crockford GP, and the Breast Cancer Linkage Consortium. Genetic linkage analysis in familial breast and ovarian cancer: results from 214 families. Am $\mathcal{H}$ Hum Genet 1993;52:678-701.

9 Narod SA, Ford D, Devilee P, et al and Breast Cancer Linkage Consortium. An evaluation of genetic heterogeneity in 145 breast-ovarian cancer families. Am $\mathcal{f}$ Hum Genet 1995; 56:254-64.
10 Steichen-Gersdorf E, Gallion HH, Ford D, et al. Familial site-specific ovarian cancer is linked to BRCAl on 17q1221. Am ₹ Hum Genet 1994;55:870-5.

11 Couch FJ, Farid LM, de Shano ML, et al. BRCA2 germline mutations in male breast cancer cases and breast cancer mutations in male breast cancer
families. Nat Genet 1996;13:123-5.

12 Couch FJ, Weber BL. Mutations and polymorphisms in the familial early-onset breast cancer (BRCA1): gene. Breast familial early-onset breast cancer (BRCA1): gene.
Cancer Information Core. Hum Mutat 1996;8:8-18.

13 Phelan CM, Lancaster JM, Tonin P, et al. Mutation analysis of the BRCA2 gene in 49 site-specific breast cance families. Nat Genet 1996;13:120-2.

14 Castilla LH, Couch FJ, Erdos MR, et al. Mutations in the BRCA1 gene in families with early-onset breast and ovarian cancer. Nat Genet 1994;8:387-91.

15 Friedman LS, Ostermeyer EA, Szabo CI, et al. Confirmation of BRCA1 by analysis of germline mutations linked to breast and ovarian cancer in ten families. Nat Genet 1994; 8:399-404.

16 Serova $\mathrm{O}$, Montagna $\mathrm{M}$, Torchard $\mathrm{D}$, et al. A high incidence of BRCA1 mutations in 20 breast-ovarian cancer families. Am 7 Hum Genet 1996;58:42-51.

17 Peelen T, Cornelis RS, van Vliet M, et al. The majority of 22 Dutch high-risk breast cancer families are due to eithe BRCA1 or BRCA2. Eur $\mathcal{F}$ Hum Genet 1996;4:225-30.

18 Struewing JP, Abeliovich D, Peretz T, et al. The carrier frequency of the BRCA1 185delAG mutation is approximately 1 percent in Ashkenazi Jewish individuals. Nat Genet 1995;11:198-200.

19 Andersen TI, Borresen AL, Moller P. A common BRCA mutation in Norwegian breast and ovarian cancer families? Am ₹ Hum Genet 1996;59:486-7.

20 Johannsson $\mathrm{O}$, Ostermeyer EA, Håkansson $\mathrm{S}$, et al. Founding BRCA1 mutations in hereditary breast and ovarian cancer in Southern Sweden. Am f Hum Genet 1996;58: 441-50.

21 Johannesdottir G, Gudmundsson J, Bergthorsson JT, et al. High prevalence of the 999del5 mutation in Icelandic breast and ovarian cancer patients. Cancer Res 1996;56: 3663-5.

22 Neuhausen S, Gilewski T, Norton L, et al. Recurrent BRCA2 6174delT mutations in Ashkenazi Jewish women affected by breast cancer. Nat Genet 1996;13:126-8.

23 Thorlacius S, Olafsdottir G, Tryggvadottir L, et al. A single BRCA2 mutation in male and female breast cancer families from Iceland with varied cancer phenotypes. Nat Genet 1996;13:117-19.

24 Shattuck-Eidens D, McClure M, Simard J, et al. A collaborative survey of 80 mutations in the BRCA1 breast and ovarian cancer susceptibility gene. Implications for presymptomatic testing and screening. $\mathcal{f} A M A$ 1995;273:53541 .

25 Hamann U, Becher H, Zimmermann T, Pella K, Bastert G, Chang-Claude J. German family study on hereditary breast/ovarian cancer. $\mathcal{f}$ Med Genet 1996;33:633-5.

26 Ganguly A, Rock MJ, Prockop DJ. Confirmation-sensitive gel electrophoresis for rapid detection of single-base differences in double-stranded PCR products and DANN fragments: evidence for solvent-induced bends in DANN heteroduplexes (published erratum appears in Proc Nat Acad Sci USA 1994;91:5217). Proc Natl Acad Sci USA 1993;90:10325-9.

27 Dong J, Chang-Claude J, Wu Y, et al. A high proportion of recurrent and novel mutations in the BRCAl gene in German breast/ovarian families with clustering of mutations in the 3 ' third of the gene. (Submitted.)

28 Lathrop GM, Lalouel JM, Julier C, Ott J. Strategies for multilocus linkage analysis in humans. Proc Natl Acad Sci USA tilocus linkage an

29 Claus EB, Risch N, Thompson WD. Genetic analysis of breast cancer in the cancer and steroid hormone study. $\mathrm{Am}$ 7 Hum Genet 1991;48:232-42.

30 Ott J. Analysis of human genetic linkage. Baltimore: The Johns Hopkins University Press, 1991

31 Schmidt S, Becher H, Chang-Claude J. Breast cancer risk assessment: use of complete pedigree information and the effect of misspecified ages at diagnosis of affected relatives. Hum Genet (in press.)

32 Margaritte-Jeannin P, Essioux L, Bonaiti-Pellié C, ClergetDarpoux F. Genetic counseling in breast cancer: sensitivity to parameter values and to available information. Ann Genet 1995;38:19-25.

33 Ford D, Easton DF, Bishop DT, Narod SA, Goldgar DE and the Breast Cancer Linkage Consortium. Risks of can-

34 Berman DB, Costalas J, Schultz DC, Grana G, Daly M, Godwin AK. A common mutation in BRCA2 that predisposes to a variety of cancers is found in both Jewish Ashkenazi and non-Jewish individuals. Cancer Res 1996;56 3409-14

35 Gudmundsson J, Johannesdottir G, Bergthorsson JT, et al. Different tumor types from BRCA2 carriers show wildtype chromosome deletions on 13q12-q13. Cancer Res 1995;55:4830-2.

36 Goggins M, Schutte M, Lu J, et al. Germline BRCA2 gene mutations in patients with apparently sporadic pancreatic carcinomas. Cancer Res 1996;56:5360-4.

37 Berry DA, Parmigiani G, Sanchez J, Schildkraut J, Winer E. Probability of carrying a mutation of breast-ovarian cancer gene BRCA1 based on family history. $\mathcal{F}$ Natl Cancer Inst gene BRCA1 based

38 Ford D, Easton DF, Bishop DT, Narod SA, Goldgar DE and the Breast Cancer Linkage Consortium. Risks of cancer in BRCA1-mutation carriers. Lancet 1994;343:692-5. 